\title{
Factors associated with depression and the relationship to quality of life among Saudi women with breast cancer
}

Monefah Al-Shammari, Amani Khalil

School of Nursing, The University of Jordan, Amman, Jordan

Received: August 4, 2020

DOI: $10.5430 /$ jnep.v11n4p43
Accepted: December 2, 2020

Online Published: December 21, 2020

URL: https://doi.org/10.5430/jnep.v11n4p43

\begin{abstract}
Background and objective: Breast cancer is the most common malignancy among women worldwide, diagnosis and treatment and the months following primary therapy associated with different psychological symptoms that affect quality of life (QoL) in most women with breast cancer. The aim of this study was to identify the relationship between depression and QoL among Saudi women with breast cancer.

Methods: Design: This is a descriptive, cross-sectional study. Methods: A convenience sample of 370 women with breast cancer was recruited from the out-clinic in King Faisal Specialist Hospital \& Research Center (KFSH\&RC). Data were collected using self-report tools derived from the Patient-Reported Outcomes Measurement Information System (PROMIS) Emotional DistressDepression-Short Form; the EORTC quality of life questionnaire (QLQ) (EORTC QLQ-C30, v.3.0 and EORTC QLQ-BR23); and from the Demographic and Clinical Data Sheet.

Results: The correlation between depression and global health status with functioning subscales for the women was negative (Pearson's $r=-.357, p<.001 ; r=-.368, p<.001$ ); whereas a positive correlation was found between depression and symptom subscales, together with its items.

Conclusions: This study shows that depression is associated with QoL among Saudi women diagnosed with breast cancer. Therefore, depression affects upon QoL among the breast cancer population. However, enhancement of mental health statuses and psychological interventions helps to reduce the severity of depression and improves health related QoL among this population.
\end{abstract}

Key Words: Quality of life, Depression, Breast cancer, Saudi women, Kingdom of Saudi Arabia

\section{INTRODUCTION}

Breast cancer is considered a fast emerging killer of women today, and is the second most common cancer overall. It is a cause of morbidity, not only for women, but also for their families. Overall among women, breast cancer is the most common cause of cancer-related mortality worldwide. ${ }^{[1,2]}$ Additionally, many women experience emotional distress and psychological symptoms following a diagnosis of breast cancer, which can persist for prolonged periods, irrespective of the clinical treatment outcome. ${ }^{[3]}$ Of all the symptoms, depression is the most prevalent psychological symptom perceived by cancer patients. ${ }^{[4]}$

In order to achieve holistic care for women who suffer from breast cancer, it is necessary to understand the prevalence of common psychological changes they experience. Indeed, depressive symptoms may progress to depression disorders,

*Correspondence: Monefah Al-shammari; Email: manoo.24@ hotmail.com; Address: School of Nursing, The University of Jordan, Amman, Jordan. 
which negatively affect overall quality of life (QoL). ${ }^{[5]}$ The untreated psychiatric co-morbidities in patients with cancer lead to many disabilities, poor QoL, and they tend to worsen patients' conditions if not adequately treated. ${ }^{[6]}$

\section{BACKGROUND}

Breast Cancer has a major impact on the health of women worldwide, and women in the Kingdom of Saudi Arabia (KSA) are no exception. Data on relevant reports from the KSA appear either scant or not provided with sufficient attention. ${ }^{[7]}$ According to the most recent report by the Saudi Cancer Registry (SCR), breast cancer constitutes $26 \%$ of all cancer incidents in Saudi women. In total, there were 1473 female breast cancer cases for the year 2010. Breast cancer ranked first among females, accounting for $27.4 \%$ of all newly diagnosed female cancers $(5,378)$ in 2010 . The age specific incidence rate (ASR) was 24.9/100,000 for the female population. ${ }^{[8]}$

The number of breast cancer cases has doubled over the past 10 years, with $50 \%$ of the cases in the Saudi population under the age of 20. ${ }^{[9]}$ Moreover, a dramatic increase in both incidence rates (350\%) and mortality rates (160\%) over the coming decade is anticipated. ${ }^{[9]}$ The incidence rate per every 100,000 population in the KSA in 2012 was estimated at 19.5-30.9, and the mortality rate for the same year estimated at 8.2-12 among Saudi women with breast cancer. ${ }^{[10]}$ Moreover, women who are diagnosed with breast cancer face multiple stressors throughout their illness trajectory. Women may experience several mental and behavioral disturbances as an adverse effect of breast cancer diagnosis and treatment. ${ }^{[11]}$ Breast cancer also affects patients' sexuality, femininity, body image, and maternal issues following mastectomies, which may lead women to face psychiatric co-morbidity. ${ }^{[12]}$ Depression is the most common psychiatric disorder in patients with cancer, with a high prevalence rate depending on the location of the tumour, clinical stage pain, functional and physical performance, and the existence of social support. ${ }^{[13]}$ The depression effect can be intense and last for extended time periods, which can lead to a reduction of a person's functionality in most life areas. ${ }^{[14]}$

Of the main outcome measures in cancer treatment is QoL, which is a multi-dimensional measure of psychological, physical, cognitive and social well-being, closely related to the illness progress, cancer treatment, underlying psychological condition, coping strategies, and social support. ${ }^{[15]}$ In a study conducted in the Gulf region, the authors found that QoL of Bahraini women with breast cancer is poor with the lowest score for emotional functioning. The authors also emphasised the need to address this issue in the Middle Eastern society. ${ }^{[16]}$ Today, QoL studies have an important role in health care, especially in chronic diseases. However, breast cancer has several complications that affect patients' lives. Therefore, it is critical for health care professionals to become familiar with the impact of a breast cancer diagnosis and its treatment on patients' QoL. ${ }^{[17]}$

Women who suffer from cancer are distressed due to illness, and most of them face depression, which leads to an increase in physical symptoms, functional disability, and a decrease in therapeutic compliance. Depression, however, can be especially difficult to diagnose, as of overlapping symptoms and co-morbid conditions. ${ }^{[18]}$ In general, depression can severely impair many important aspects of one's life. The effects of depression are wide ranging, and have a strong and complex relationship with cancer, which is considered as a main source of distress that can have a profound impact on the QoL of breast cancer survivors. ${ }^{[19,20]}$ There is also a significant relationship and negative correlation between depression and QoL among this population. ${ }^{[21,22]}$

In order to improve QoL for breast cancer patients, social support is imperative throughout their treatment and recovery. Accordingly, social support can help to cope with all chronic, life-threatening illnesses that prove detrimental to patients' well-being. ${ }^{[22]}$ Nevertheless, economic challenges to one's life are viewed as the main predictor of low QoL, as better financial situations often produce better QoL. Further, many studies have demonstrate that low socio-economic statuses result in negative physical, psychological and social well-being effects. ${ }^{[23-25]}$

A variety of articles conducted in the KSA were published on different facets (e.g. epidemiology, knowledge of breast cancer, breast self-exam, etiological factors, metastasis and rate of survival) in regards to breast cancer through a period in excess of thirty years. ${ }^{[7]}$ However, the fact that depression is a result of breast cancer is little known in the KSA. In addition, QoL is a relatively new concept in Saudi research, and there are no articles that had been conducted to specifically assess the level of QoL among Saudi women with breast cancer. Therefore, the current study describes depression and QoL, as well as evaluates the association between these variables among Saudi women with breast cancer.

\section{Methodology}

\subsection{Study design}

A descriptive correlational, cross-sectional design was used to identify the relationship between depression and QOL among women with breast cancer in the KSA. The method used to collect data was through self-reported questionnaire in regards to depression and QoL. 


\subsection{Population and sample}

The target population consisted of only breast cancer women patients in the Riyadh region, KSA. The accessible population was all women with breast cancer at King Faisal Specialist Hospital \& Research Centre (KFSH\&RC). The sample was recruited using a nonprobability convenience technique sample. The inclusion criteria required for the women were: 1) free of major mental disorders or cerebrovascular disease; 2) 18 years and above, and; 3) able to understand Arabic. Therefore, the exclusion criteria included the presence of a coexisting terminal illness or using antidepressant medication when participating, and being a non-Saudi woman. The sample size was calculated using G power, ${ }^{[27]}$ for Pearson Correlation Moment Product Coefficient (Pearson $r$ ) as test statistics. The results showed that the required sample size was 366 ; there were 370 females accepted to participate.

\subsection{Setting}

The current study was carried out in King Faisal Specialist Hospital \& Research Centre (KFSH\&RC) in the KSA, which enjoys the recognition of having the largest cancer facility in the Gulf region. Patients with cancer are treated in this centre, where they have been treating cancer since 1975. In 2012, this centre was accredited by the World Health Organization (WHO) as a Collaborating Centre for Cancer Prevention and Control. ${ }^{[28]}$

\subsection{Ethical consideration}

Ethical approval was obtained from the University of Jordan - School of Nursing and the target institutions in the KSA. Women who participated in the study were met and provided detailed information regarding the study, emphasising the right of the subject to non-participation, and ensured data confidentiality was maintained throughout the study. They were asked to verbally consent for participation, and were informed that they can quit the research at any time they wish.

\subsection{Procedure}

Women who were interested in the study were invited to participation by asking for their consent before starting the face-to-face interviews. Hence, their permission was taken following a public invitation to the women to participate and a distributed flyer containing the aim of the study and criteria for eligibility. Participants were informed that filling the questionnaires would be conducted one time only while waiting in the clinic. The questionnaires (PROMIS) Emotional distress-Depression, EORTC QLQ-C30, and demographic information were asked to be filled in by the women. In addition, the researcher was available for all the participants for reading and filling the questionnaires, which was filled

Published by Sciedu Press out by the participants.

\subsection{Instruments}

The data were collected using an Arabic version of the scales. The instruments were:

1) The first part of the questionnaire was prepared by the researcher to collect demographic data regarding the study sample based on hospital records. It mainly addressed the following information: age, marital status, cancer staging, and types of treatments (chemotherapy, radiotherapy, surgical treatment, or combined), employment, co-morbidities and educational levels.

2) Depression was measured using The Patient-Reported Outcomes Measurement Information System (PROMIS) Emotional distress-Depression- short form scale. The measurement was developed to assess the clinical signs of depression in the clinical settings, and thus, it included eight items that requested the women to rate their depressive feelings based on a scale (never (0) to always (5)), with the complete range from 8-40. These scores were able to be obtained by summarising the raw scores from the eight items, with a T-score table utilised in the identification of the T-score for the participants' overall raw score. The scores were marked as follows: < 55 (none-slight); between 55.0 and 59.9 (mild depression); between 60.0 and 69.9 (moderate depression); and $>70$ (severe depression). ${ }^{[29]}$ In addition, this measures the negative mood, negative views for the self, decreases the positive effect, and negative social cognition. ${ }^{[30]}$ Moreover, the scale was translated into the Arabic language, and used among elderly people within the Jordanian culture, which showed high internal consistency values with Cronbach's alpha of $.875 .^{[31]}$

3) The European Organisation for Research and Treatment of Cancer Specific Version (EORTC QLQ-C30, v.3.0) assessed the QoL translated into Arabic and was validated. ${ }^{[32,33]}$ Global health, physical, role, emotional, cognitive, social functioning, fatigue, nausea/ vomiting, pain, and financial impact are all explored by the EORTC QLQ-30. The QoL Breast Cancer Specific Version ${ }^{[32,33]}$ was also used and translated into Arabic. The EORTC QLQ-BR23 incorporates five domains: therapy side effects, arm symptoms, breast symptoms, body image, and sexual functioning. Scores for these questions range between 0 and 100. For scales that evaluate global health and function, a higher score represents higher levels of functioning and health. For scales that evaluate symptoms, a higher score indicates more problems and higher level of symptoms.

\subsection{Statistical analysis}

Data were analysed using the Statistical Package for Social Sciences (SPSS). Descriptive statistics were used to describe 
and summarise the continuous variables (depression and QoL). Moreover, frequencies or percentage statistics were used to describe and summarise the nominal and ordinal variables, such as demographics. ANOVA, independent sample $t$-test, and correlation coefficient analysis tests were also used to determine whether depression would differ in terms of demographic characteristics. A partial correlation coefficient test was used to determine the relationship between the depression and QoL after controlling the demographic variables. All the tests were two-tailed with an alpha level of 0.05 .

\section{STUDY'S FINDINGS}

In the current study, a total of 370 women participated. As presented in Table 1 below, the mean age of the sample was 46.60 years $(\mathrm{SD}=11.03)$, ranging from 18 to 80 years. Married women represented $248(67.0 \%)$ of the total sample size. Of the sample, $46.5 \%$ of them had a lower-secondary education, while $50.7 \%$ were unemployed. $73.5 \%$ of the participants did not suffer from any chronic diseases except $26.5 \%$ had a co-morbid disease and $70.0 \%$ of those were receiving combined treatment.

Table 1. Women's demographics' data $(\mathrm{N}=370)$

\begin{tabular}{lll}
\hline Variable & N (\%) & M (SD) \\
\hline Age & & 46.60 years \\
(SD = 11.03)
\end{tabular}

The mean score of the depression scale was 17.13 (SD $=$ 6.20 ), with the median at 16 . Furthermore, $50.8 \%$ of the women had non to slight depression; and $32.2 \%$ had mild depression. The last percentage was $17 \%$ for women who suffered from moderate to severe depression. In this case, assessment, follow-up and suitable treatment is essential for clinical depression. ${ }^{[29]}$

\subsection{Quality of life scores}

Participants had a mean score for the global health subscale of 63.15 ( $\mathrm{SD}=18.14$ ). Among functional subscales, the physical functioning item scored the highest at $93.23(\mathrm{SD}=$ 4.17), whereas the social functioning item scored the lowest at $76.80(\mathrm{SD}=16.45)$. On the symptom subscales, the worst was the insomnia item 49.09 at $(\mathrm{SD}=76.86)$, followed by appetite loss and dyspnoea items. Using QOL-BR23, the functional subscales found the future perspective item the lowest at 36.03 ( $\mathrm{SD}=32.62$ ), which indicates poor functioning; whereas, the sexual functioning item scored the highest at $91.86(\mathrm{SD}=11.26)$. Among the symptom subscales, the upset by hair loss item was found to be high at 63.42 (SD = 41.08), which indicated worse functioning, followed by the arm symptoms item at 14.91 (7.50).

The Pearson correlation coefficient test showed that there is a statistically significant negative correlation between the age and depression total score $(r=-.216, p<.001)$. Therefore, the youngest women had a higher total score of depression. Comparatively, there were no statistically significant differences in mean scores of depression based on women's demographics (see Table 2).

The test findings showed a negative correlation between depression and the QLQ-C30- global health status, functioning subscales $(r=-.357, p<.001 ; r=-.368, p<.001)$, and positive correlation between depression and QLQ-C30- symptom subscales and items $(r=.284, p<.001)$ (see Table 3). Moreover, the findings showed a negative correlation between depression and QLQ-BR23-functional subscales ( $r=-.431$, $p<.001)$, and found a positive correlation between depression and QLQ-BR23-symptom subscales and items $(r=.311$, $p<.001 ; r=.313, p<.001$ ) (see Table 4 ). The results showed that the influences of confounding variables on the main association did not change the original correlation. In other words, the controlling variable (age) has no significant effects on the strength and direction of the relationships between depression and QoL.

\section{Discussion}

The current study is the first Saudi study to investigate the relationship between depression and QoL among Saudi women with breast cancer. The results determined that $49.2 \%$ of the total sample had from mild to severe depression; psychological assessment or interventions was not provided to them. Moreover, the findings regarding prevalence of depression are considered to be general high worldwide. Studies from 
Western countries have shown that the prevalence of depres- depression from Asian studies is $12.5 \%$ to $31 \%$. ${ }^{[3]}$ sion ranges from $1 \%$ to $56 \%$, whereas the prevalence of

Table 2. Differences of depression based on women's demographics

\begin{tabular}{|c|c|c|c|c|}
\hline Variable & $\mathbf{N}$ & Depression M (SD) & $T$ & $p$-value \\
\hline \multicolumn{5}{|l|}{ Marital Status } \\
\hline Married & 122 & $17.30(6.75)$ & \multirow{2}{*}{.365} & \multirow{2}{*}{.200} \\
\hline Unmarried & 248 & $17.05(5.92)$ & & \\
\hline \multicolumn{5}{|l|}{ Educational Level } \\
\hline Lower-secondary education & 220 & $16.63(6.29)$ & \multirow{2}{*}{-1.89} & \multirow{2}{*}{.507} \\
\hline Upper-secondary education & 150 & 17.87(6.00) & & \\
\hline \multicolumn{5}{|l|}{ Employment Status } \\
\hline Employed & 130 & $18.17(6.14)$ & \multirow[t]{2}{*}{2.39} & \multirow[t]{2}{*}{.793} \\
\hline Not employed & 240 & 16.57(6.17) & & \\
\hline \multicolumn{5}{|l|}{ Presence of Co-morbid Disease } \\
\hline Yes & 98 & $15.74(6.32)$ & & \\
\hline No & 272 & 17.63(6.09) & -2.60 & .764 \\
\hline
\end{tabular}

Table 3. Pearson r-correlation of the main variables (Depression and QoL- QLQ-C30)

\begin{tabular}{ll}
\hline Variable & $\boldsymbol{r}$ \\
\hline Global Health Status & $=-.357, p=.000$ \\
Functional Subscales & $=-.368, p=.000$ \\
$\quad$ Physical Functioning & $=-.040, p=.441$ \\
$\quad$ Role Functioning & $=-.243, p=.000$ \\
Emotional Functioning & $=-.091, p=.079$ \\
Cognitive Functioning & $=-.419, p=.000$ \\
Social Functioning & $=.284, p=.000$ \\
Symptom Subscales & $=.256, p=.000$ \\
Fatigue & $=.183, p=.000$ \\
Nausea and Vomiting & $=.279, p=.000$ \\
Pain & $=.052, p=.321$ \\
Dyspnoea & $=.081, p=.121$ \\
Insomnia & $=.200, p=.000$ \\
Appetite Loss & $=.051, p=.328$ \\
Constipation & $=.207, p=.000$ \\
Diarrhoea & $=.368, p=.000$ \\
Financial Difficulties &
\end{tabular}

The prevalence of depression in breast cancer survivors in this study is not different from that reported in corresponding Asian and Western studies. In addition, the findings show the prevalence of depression was higher than those reported on Jordanian patients, and lower than undertaken with patients in Nigeria, which used different scales, such as the Hospital Anxiety and Depression Scale (HADS) and the Becks Depression Inventory (BDI-II). ${ }^{[34,35]}$ Further, it is important to know that depression has been treated as a categorical variable (as 'present' or 'absent') based on the PROMIS and many other rating scales' score or clinical judgment. The prevalence of depression in breast cancer survivors varies greatly from low to high depending on the tool of measurement used and how it has been defined. ${ }^{[3]}$ Many factors may play a role in these results, such as the difference in socio-economic statuses. These findings strongly focus on the importance of the need for psychological counselling, consultation, and follow-up for these women to reduce the severity of depression.

Table 4. Pearson r-correlation of the main study variables (Depression and QoL- QLQ-BR23)

\begin{tabular}{ll}
\hline Variable & $\boldsymbol{R}$ \\
\hline Functional Subscales & $=-.431, p=.000$ \\
Body Image & $=-.503, p=.000$ \\
$\quad$ Sexual Functioning & $=.010, p=.854$ \\
Sexual Enjoyment & $=.002, p=.962$ \\
Future Perspective & $=-.376, p=.000$ \\
Symptom Subscales & $=.311, p=.000$ \\
Systemic Therapy Side Effects & $=.305, p=.000$ \\
Breast symptoms & $=.254, p=.000$ \\
Arm Symptoms & $=.147, p=.005$ \\
Upset by Hair Loss & $=.313, p=.000$ \\
\hline
\end{tabular}

The current study shows a mean global health score (QL2) for the QLQ-C30 with $\mathrm{M}=63.15$ ( $\mathrm{SD}=18.14$ ), which was close to many national and international figures. The global health score from a study from Bahrain was $\mathrm{M}=63.9$ (SD $=21.3),{ }^{[16]}$ and from Lebanon the scale scored as $\mathrm{M}=58.46$ ( $\mathrm{SD}=23.86) \cdot{ }^{[36]}$ In the functional subscale of the QLQ-C30 scale, physical functioning scored the highest $(M=93.23$, 
$\mathrm{SD}=4.17)$, which is higher than that reported in Lebanon $(\mathrm{M}=77.37, \mathrm{SD}=23.22),{ }^{[36]}$ and that reported in Bahrain $(\mathrm{M}$ $=74.9, \mathrm{SD}=21.7),{ }^{[16]}$ as well as Malaysia who scored $\mathrm{M}$ $=75.33(\mathrm{SD}=21.41),{ }^{[37]}$ and that reported in Jordan $(\mathrm{M}=$ 69.6,SD $=26.1),{ }^{[34]}$ although consistent with Germany (M $=93.2, \mathrm{SD}=6.8) \cdot{ }^{[38]}$ Regarding the functional subscales of the QLQ-BR23, sexual functioning had the highest mean score of $91.86(\mathrm{SD}=11.26)$; this score is higher than other reported scores in Bahrain, Kuwait, Malaysia, and Brazil from $25.92(\mathrm{SD}=29.77)$ to $72.41(\mathrm{SD}=34.54){ }^{[16,37,39,40]}$ The functional status of these women highly depends on their family roles as wives and workers; these results indicate that the functional abilities were not significantly affected or decreased.

Regarding the symptom subscale of the QLQ-C30 scale, the most distressing symptom score was Insomnia $(\mathrm{M}=49.09$, $\mathrm{SD}=76.86$ ). This result is higher than the reported results in Bahrain, Kuwait, Lebanon, Malaysia, and Brazil from 23.18 $(\mathrm{SD}=14.17)$ to $42.7(\mathrm{SD}=28.2) .^{[16,37,39,40]}$ Based on the QLQ-BR23, upset by hair loss had the lowest mean score at $63.42(\mathrm{SD}=41.08)$. These scores are higher than those reported in Bahrain, Brazil, and Malaysia from 37.43 (SD = $44.12)$ to $46.3(\mathrm{SD}=42.9),{ }^{[16,37,40]}$ but lower than reported in Jordan at69.8 $(\mathrm{SD}=43.0) \cdot{ }^{[34]}$ Meanwhile, Saudi and Islamic culture totally separates the women's and men's social and academic activities. As a result, women enjoy being exposed without a Hijab in-front of other ladies from the Saudi society, such as at weddings and in teaching institutions. Therefore, many women's social activities are conducted and run by women without being at risk of men's exposure. However, this cultural factor may constrain the Saudi women diagnosed with cancer and treated with chemotherapy to enjoy these events with other women due to the significant changes in their body image.

The findings suggest that the subscales of QoL among Saudi females who suffer from breast cancer are high and satisfactory in comparison to other women around the world. Functional status and symptoms of QoL are high among Saudi women with breast cancer with financial status and social relations playing an important role in increasing QoL. What is more, the results showed that there is a statistically significant negative correlation between age and depression. The youngest women with breast cancer had a higher total score of depression compared to older women. In studies of women of all ages with breast cancer, younger women typically report responses that indicated a greater likelihood of clinical depression or greater severity of depressive symptoms, a heightened level of stress, and/or worse QoL when compared with older women with breast cancer. ${ }^{[41]}$ Younger women with breast cancer are at greater risk of psychoso- cial distress than older ones, as younger women contract the disease as a life-threatening diagnosis. ${ }^{[19]}$ Breast cancer in young women is compounded by the fact that they must deal with an array of unique challenges, such as: loss of fertility, diagnosis during pregnancy, childcare, early career disruptions, and an increased risk of a second breast cancer. ${ }^{[42]}$

The association between depression and QoL was a negative weak correlation between global health subscale (QL2) for the QLQ-C30 and depression; higher levels of global health status were associated with lower severity of depression. Moreover, the findings showed a negative correlation between functioning subscale for the QLQ-C30 and depression, which means a higher level of functioning status was associated with lower severity of depression. Among symptom subscale for the QLQ-C30, a positive correlation with depression was found; however, this association was not affected by other confounding variables except for ageing. This is an agreement with the findings of other studies that were conducted among the same population in turkey and Malaysia. ${ }^{[15,22]}$ In addition, the findings showed a negative correlation between a functioning subscale for QLQ-BR23 and depression, and a positive correlation between symptom subscale for QLQ-BR23 and depression, which is in agreement with the study from Malaysia. ${ }^{[15]}$ No Saudi studies had investigated this association among women with breast cancer previously. Indeed, these findings suggest that the QoL status and level of depression were high. Even though the proportion of depression among the target population was high, the quality of life scored high compared to other nations. Moreover, the presence of depression was noted among these women due to the illness itself and/or treatments. This finding could be explained by many reasons; firstly, Saudi governance provides incentives to Saudi women with breast cancer, such as high quality health insurance and social support. These factors increase their QoL, which is associated with living conditions and social and financial support.

The Saudi government provides free care and treatment for Saudi women with breast cancer, as well as monetary assistance and housekeeping services to breast cancer patients. Moreover, the government provides free travelling tickets and paid expenses for breast cancer patients living outside treatment care hospitals and centres. In addition, Saudi society is a traditional and conservative society that surrounds the woman patient with family members and relatives, thus creating a net of social support that improves the QoL of these women. This corresponds with other research studies that have demonstrated that high levels of personal economy help to improve women's QoL. ${ }^{[44]}$ Similarly, high better socio-economic level has been shown to correlate with 
better treatment responses and recovery for patients, due to fewer financial restraints, as well as less stress due to work. ${ }^{[4]}$ This has also been shown in a study from Ethiopia, which found that patients with economic issues generally present with poor QoL. ${ }^{[45]}$ Similarly, studies from Iran, Pakistan, and Nigeria have shown corresponding data. ${ }^{[28,46,47,49]}$ These financially related findings often relate to the fact that chemotherapy is prolonged, and thus, an expensive form of treatment in many countries. Meanwhile, in Ethiopia, this is even more acutely apparent, as there are only a limited amount of facilities available for chemotherapy treatment, which results in the patients needing to travel extreme distances in order to receive treatment, and thus, increases the level of expenditure required.

For future studies, more focus should be provided to one's socio-economic status on QoL and psychological issues of women with breast cancer. Despite the presence of high depression among Saudi women with breast cancer, this did not affect their QoL, which normally remained high, as Saudi women with breast cancer do not face extreme financial and employment difficulties, and they are provided with medical, social and health services that augment their QoL.

\section{Conclusion}

Depression is often relevant for women with breast cancer, as it reduces QoL. The current study found that QoL subscales were not strongly associated with depression. The main variables of this study were shown to be high among Saudi women with breast cancer for the socio-economic reasons mentioned previously. Therefore, early identification of depression played important roles in the improvement in effective cancer treatment among those women. ${ }^{[43]}$ In order to decrease the intensity of depression and the improvement of health conditions related to the quality of life among Saudi women with breast cancer, we should focus on the enhancement of one's mental health status and psychological interventions. What is more, understanding the effectiveness and interventions on psychological and physical wellbeing among women with breast cancer on different conditions, such as religious, social or physical, showed a requirement for further longitudinal or experimental research studies.

\section{Limitations}

One of the limitations that should be stated relates to the main variables, which were measured through questionnaires and could potentially have resulted in generating false positives or negative cases. Another limitation is a convenience sampling method, which can be easy applied. As a result, this may cause sampling bias, which will result in a lack of generalisability. ${ }^{[50]}$

\section{ACKNOWLEDGeMENTS}

I would like to thank the University of Jordan, Dr. Ayman M. Hamdan-Mansour, Ms. Muneerah Almutairi, King Faisal Specialist Hospital \& Research Centre in Riyadh, and all the participants who helped me to undertake and complete the current study.

\section{Conflicts of InTEREST Disclosure}

The authors declare that there is no conflict of interest.

\section{REFERENCES}

[1] Jemal A, Bray F, Center MM, et al. Global cancer statistics. CA: A Cancer Journal for Clinicians. 2011; 61(2): 69-90. PMid:21296855 https://doi.org/10.3322/caac. 20107

[2] Youlden DR, Cramb SM, Dunn NA, et al. The descriptive epidemiology of female breast cancer: an international comparison of screening, incidence, survival and mortality. Cancer Epidemiology. 2012; 36(3): 237-248. PMid:22459198 https : //doi .org/10.1016/j . canep. 2012.02 .007

[3] Zainal NZ, Nik-Jaafar NR, Baharudin A, et al. Prevalence of depression in breast cancer survivors: a systematic review of observational studies. Asian pacific Journal of Cancer Prevention. 2013; 14(4): 2649-56. PMid:23725190 https ://doi .org/10.7314/AP JCP. 2013. 14.4. 2649

[4] Takahashi T, Hondo M, Nishimura K, et al. Evaluation of quality of life and psychological response in cancer patients treated with radiotherapy. Radiation Medicine. 2008; 26(7): 396-401. PMid:18769996 https://doi.org/10.1007/s11604-008-0248-5

[5] Wong WS, Fielding R. Change in quality of life in Chinese women with breast cancer: changes in psychological distress as a predic- tor. Supportive Care in Cancer Journal. 2007; 15(11): 1223-1230. PMid:17205280 https ://doi.org/10.1007/s00520-006-019 $0-\mathrm{y}$

[6] Singer S, Das-Munshi J, Brahler E. Prevalence of mental health conditions in cancer patients in acute care - a meta-analysis. Annals of Oncology. 2010; 21: 925-930. PMid:19887467 https: //doi.org/10.1093/annonc/mdp515

[7] Al Diab A, Qureshi S, Al Saleh KA, et al. Review on breast cancer in the Kingdom of Saudi Arabia. Middle-East J Sci Res. 2013; 14(4): $532-43$.

[8] Saudi Cancer Registry. Cancer incidence report, Saudi Arabia, 2006, Kingdom of Saudi Arabia: Ministry of Health. 2010.

[9] Ibrahim EM, Zeeneldin AA, Sadiq BB, et al. The present and the future of breast cancer burden in the Kingdom of Saudi Arabia. Medical Oncology. 2008; 25(4): 387-393. PMid:18317955 https://doi.org/10.1007/s12032-008-9051-5

[10] American Cancer Society. Global Cancer Facts \& Figures, 3rd Edition, Atlanta, USA. 2015; 1-62. 
[11] Saniah AR, Zainal NZ. Anxiety, depression and coping strategies in breast cancer patients on chemotherapy. Malaysian Journal of Psychiatry. 2010; 19(2).

[12] Sharma A, Zhang J. Depression and its predictors among breast cancer patients in Nepal. Journal of Psychiatry. 2015.

[13] So WK, Marsh G, Ling WM, et al. Anxiety, depression and quality of life among Chinese breast cancer patients during adjuvant therapy. European Journal of Oncology Nursing. 2010; 14(1): 17-22. PMid:19734087 https://doi.org/10.1016/j.ejon.2009.07 .005

[14] Efthimiou K, Psoma M. Lewinsohn's cognitive behavioral group therapy course for depression: Structure, application and efficacy Encephalos. 2012; 49: 60-66. https://doi .org/10.1007/s152 00-012-1022-4

[15] Ng CG, Mohamed S, See MH, et al. Anxiety, depression, perceived social support and quality of life in Malaysian breast cancer patients: a 1-year prospective study. Health and Quality of Life Outcomes. 2015; 13(1): 205. PMid:26715073 https://doi.org/10.1186/ s12955-015-0401-7

[16] Jassim G, Whitford D. Quality of life of Bahraini women with breast cancer: across sectional study. BMC Cancer. 2013; 13: 212 PMid:23622020 https : //doi .org/10.1186/1471-2407-13-2 12

[17] Safaee A, Moghimi-Dehkordi B, Zeighami B, et al. Predictors of quality of life in breast cancer patients under chemotherapy. Indian Journal of Cancer. 2008; 45(3): 107-111. PMid:19018114 https://doi.org/10.4103/0019-509X.44066

[18] Singh TB, Singh LJ, Mhetre BB. Breast cancer and depression: issues in clinical care. Medical Journal of Indonesia. 2012.

[19] Reyes-Gibby C, Anderson KO, Morrow PK, et al. Depressive Symptoms and Health-Related Quality of Life in Breast Cancer Survivors. Journal of Women Health. 2012; 21(3): 311-318. PMid:22060256 https://doi.org/10.1089/jwh.2011.2852

[20] Verduyn C. Cognitive-behavioral therapy for depression in children and adolescents. Tidsskrift for Norsk Psykologforening. 2011; 48: 34-39.

[21] Dragomir B, Fodoreanu L, Rancea A. The impact of depression and anxiety on the quality of life in nonmetastatic breast cancer patients in postoperative evaluation. Clujul Medical. 2013; 86(1): 48.

[22] Tuncer OF. Psychological well - being of cancer patients: Depression, anxiety and quality of life among Turkish cancer patients, Master Thesis, Tilburg University, Turkey. 2011.

[23] Yoo GJ, Levine EG, Aviv C, et al. Older women, breast cancer, and social support. Supportive care in Cancer. 2010; 18(12): 1521-1530. PMid:20967554 https://doi.org/10.1007/s00520-009-077 4-4

[24] Nayak MG, George A, Vidyasagar MS, et al. Quality of life among cancer patients. Indian journal of palliative care. 2017; 23(4): 445 PMid:29123353 https://doi.org/10.4103/IJPC.IJPC_82_1 7

[25] Gangane N, Khairkar P, Hurtig AK, et al. Quality of life determinants in breast Cancer patients in central rural India. Asian Pacific Journal of Cancer Prevention: APJCP. 2017; 18(12): 3325.

[26] Pandey M, Thomas BC, SreeRekha P, et al. Quality of life determinants in women with breast cancer undergoing treatment with curative intent. World journal of surgical oncology. 2005; 3(1): 63 . PMid:16188030 https://doi.org/10.1186/1477-7819-3-63

[27] Faul F, Erdfelder E. GPOWER: A priori, post-hoc, and compromise power analyses for MS-DOS [Computer program]. Bonn, FRG: Bonn University, Department of Psychology. 1992.

[28] King Faisal Specialist Hospital and Research Centre. 2013.
[29] American Psychiatric Association (APA). Diagnostic and statistical manual of mental disorders. 5th ed. Washington, DC: American Psychiatric Association. 2013. https://doi.org/10.1176/appi.b ooks. 9780890425596

[30] Cella D, Riley W, Stone A, et al. The Patient-Reported Outcomes Measurement Information System (PROMIS) developed and tested its first wave of adult self-reported health outcome item banks: 2005-2008. Journal of Clinical Epidemiology. 2010; 63(11): 11791194. PMid:20685078 https://doi.org/10.1016/j.jclinepi .2010 .04 .011

[31] Hamdan- Mansour A. Psychological and social wellbeing of older persons in Jordan. European Psychiatry. 2015; 30(1): 28-31. https : //doi.org/10.1016/S0924-9338(15) 31107-X

[32] Pereira S, Fontes F, Sonin T, et al. Neurological complications of breast cancer: study protocol of a prospective cohort study. BMJ Open. 2014; 4(10). PMid:25351600 https ://doi .org/10.1136/ bmjopen-2014-006301

[33] Awad MA, Denic S, El-Taji H. Validation of the European Organization for Research and Treatment of Cancer Quality of Life Questionnaires for Arabic-speaking Populations. Annals of the New York Academy Sciences. 2008; 1138: 146-154. PMid:18837895 https://doi.org/10.1196/annals.1414.021

[34] Abu-Helalah M, Al-Hanaqta M, Alshraideh H, et al. Quality of life and psychological well-being of breast cancer survivors in Jordan. Asian Pac J Cancer Prev. 2014; 15(14): 5927-36. PMid:25081724 https ://doi.org/10.7314/APJCP. 2014.15.14.5927

[35] Akin-Odanye EO, Asuzu CC, Popoola OA. Measured effect of some socio-demographic factors on depression among breast cancer patients receiving chemotherapy in Lagos State University Teaching Hospital (LASUTH). African Health Sciences. 2011; 11(3).

[36] Abu-Saad Huijer H, Abboud S. Health-related quality of life among breast cancer patients in Lebanon. European Journal of Oncology Nursing. 2012; 16(5): 491-497. PMid:22257429 https://doi.or $\mathrm{g} / 10.1016 / \mathrm{j}$.ejon. 2011.11.003

[37] Edib Z, Kumarasamy V. Quality of Life among Female Breast Cancer Patients in a University Hospital in Malaysia. British Journal of Medicine \& Medical Research. 2015; 6(5): 453-462. https: //doi.org/10.9734/BJMMR/2015/15065

[38] Waldmann A, Pritzkuleit R, Raspe H, et al. The OVIS study: health related quality of life measured by the EORTC QLQ-C30 and-BR23 in German female patients with breast cancer from Schleswig-Holstein. Quality of Life Research. 2007; 16(5): 767-776. PMid:17286196 https://doi.org/10.1007/s11136-006-9161-5

[39] Alawadi SA, Ohaeri JU. Health-related quality of life of Kuwaiti women with breast cancer: a comparative study using the EORTC Quality of Life Questionnaire. BMC Cancer. 2009; 9(1): 222 PMid:19586536 https://doi.org/10.1186/1471-2407-9-2 22

[40] Lôbo SA, Fernandes AFC, Almeida PCD, et al. Quality of life in women with breast cancer undergoing chemotherapy. Acta Paul Enferm. 2014; 27(6): 554-559. https://doi.org/10.1590/1982 $-0194201400090$

[41] Howard-Anderson J, Ganz PA, Bower JE, et al. Quality of life, fertility concerns, and behavioral health outcomes in younger breast cancer survivors: a systematic review. Journal of the National Cancer Institute. 2012; 104(5): 386-405. PMid:22271773 https: //doi.org/10.1093/jnci/djr541

[42] Canadian Breast Cancer Foundation. Workshop: Research Opportunities to Address Breast Cancer in Young Women, Canadian Institutes of Health Research. 2012; September 13 \& 14, Montreal, Quebec, Report: 1-19. 
[43] Ardebil MD, Bouzari Z, Shenas MH, et al. Depression and health related quality of life in breast cancer patients. The journal of the Pakistan Medical Association. 2013; 63(1): 69-71.

[44] Costanzo ES, Lutgendorf SK, Mattes ML, et al. Adjusting to life after treatment: distress and quality of life following treatment for breast cancer. British Journal of Cancer. 2007; 97(12): 1625-1631. PMid:18000503 https://doi.org/10.1038/sj.bjc.6604091

[45] Hassen AM, Taye G, Gizaw M, et al. Quality of life and associated factors among patients with breast cancer under chemotherapy at Tikur Anbessa specialized hospital, Addis Ababa, Ethiopia. PloS One. 2019; 14(9): e0222629. PMid:31539399 https://doi.org/ 10.1371/journal . pone. 0222629

[46] Bekele MA. Assessing the quality of life among patients with breas cancer at Tikur Anbassa specializd hostpital, Addis Ababa, Ethiopia
(Master's thesis, Oslo and Akershus University College of Applied Sciences). 2016.

[47] Jaiyesimi AO, Sofela EA, Rufai AA. Health related quality of life and its determinants in Nigerian breast cancer patients. African Journal of Medicine and Medical Sciences. 2007; 36(3): 259-265.

[48] Safaee A, Moghimi-Dehkordi B, Zeighami B, et al. Predictors of quality of life in breast cancer patients under chemotherapy. Indian Journal of Cancer. 2008; 45(3): 107. PMid:19018114 https : //doi.org/10.4103/0019-509x.44066

[49] Mohsin S, Rehman MU, Azam N, et al. Comparison of quality of life of cancer patients undergoing chemotherapy in a tertiary care hospital, rawalpindi. Pakistan Armed Forces Medical Journal. 2016; 66(1): 83-87.

[50] Polit DF, Beck CT. Nursing research: Generating and assessing evidence for nursing practice. Lippincott Williams \& Wilkins. 2008. 